\title{
Associations between changing climate and body condition over decades in two southern hemisphere passerine birds
}

\author{
Janet L. Gardner ${ }^{1 *}$ (D) Eleanor Rowley ${ }^{2}$, Perry de Rebeira ${ }^{3}$, Alma de Rebeira ${ }^{3}$ and Lyanne Brouwer ${ }^{1,4}$
}

\begin{abstract}
Background: Climate change presents considerable challenges for endotherms because they must maintain high, relatively constant body temperatures across a range of environmental conditions to ensure survival and optimise performance. Individuals exposed to changing weather must manage energy and water allocation to maintain thermal homeostasis, with consequences for body condition, and hence there is potential for selection because body condition is strongly linked to fitness. Understanding how weather drives changes in body condition is therefore fundamental to understanding how fitness is affected by climate change. Here we test for associations between weather and body condition and how this changes over time, in two co-existing species of small insectivorous passerines, the red-winged fairy-wren, Malurus elegans and white-browed scrubwren, Sericornis frontalis, that have been the subject of a ringing study for 39 years in temperate south-western Australia. The study populations have experienced increases in minimum temperatures in winter and summer as well as decreases in the frequencies of days with thermal minima $<5^{\circ} \mathrm{C}$, but the summer climate remains relatively mild with few days experiencing thermal maxima $>35^{\circ} \mathrm{C}$. Although, warming temperatures may reduce thermoregulatory costs, repeated exposure to hot conditions has been shown to have negative effects on body condition. Thus, we predict that the reduction over time in daily minima $<5{ }^{\circ} \mathrm{C}$, along with the influence of increased maximum and minimum temperatures in summer and winter, will have positive effects on body condition.

Results: In accordance with thermoregulatory predictions, colder daily minima in the range $1-19{ }^{\circ} \mathrm{C}$ prior to capture were associated with reduced body condition in winter in both species. Furthermore, in summer, in fairy-wrens but not scrubwrens, warmer daily maxima were associated with increasing body condition, and repeated exposure to temperatures $>30^{\circ} \mathrm{C}$ over consecutive days was negatively associated with body condition. Body condition increased over the 39 years of the study for fairy-wrens but there was no change in scrubwrens, which is consistent with observed within-season associations between body condition and weather, and the change in climate over time.

Conclusions: We show that associations between body condition and weather variables are complex and dynamic, with seasonal trends in body condition resulting from a balance between multiple, competing weather variables. Moreover, temporal trends in body condition over years could be predicted from the relative strength of seasonal trends and the direction and magnitude of changing climate. Because body condition is predicted to be strongly tied to both reproduction and survival, changes in climate may be having complex and far reaching consequences for demography mediated through shifts in body condition. Finally, subtle differences in the sensitivities of the species to weather variables led to different trends in condition over time which may be associated with differences in the capacity for behavioural thermoregulation. Understanding the causes of such sensitivities is vital in improving capacity to predict species responses to climate change.
\end{abstract}

Keywords: Behavioural thermoregulation, Body condition, Climate change, Meliphagoidea, Passerine birds, Australia

\footnotetext{
* Correspondence: janet.gardner@anu.edu.au

'Division of Ecology \& Evolution, Research School of Biology, Australian

National University, Canberra, ACT 0200, Australia

Full list of author information is available at the end of the article
} 


\section{Background}

There is abundant evidence that organisms are affected by climate change but demonstrations of how climate drives changes in fitness, and the links between selection and population demography are surprisingly rare. Endotherms must maintain high, relatively constant body temperatures across a range of environmental conditions so climate change has potential to impose additional thermoregulatory costs. When exposed to environmental conditions outside the thermoneutral zone (TNZ) - the range of conditions where no additional energy and water are specifically allocated to maintain homeostasis $[1,2]$ - additional energy may be required to maintain body temperature, while additional water may be required for evaporative cooling at high temperatures. Managing energy and water budgets in conditions outside the TNZ can have negative consequences for body condition, defined as the reserve component of body mass after accounting for structural size [1]. Because body condition is strongly tied to both survival and reproduction [3], understanding how climate drives changes in body condition is critical to understanding how fitness is affected by climate change.

Much of the research in this area has focused on the consequences of exposure to rare but potentially lethal extreme events which can have dramatic immediate impacts on wild populations. Exposure to severe heatwaves with temperatures above critical thresholds can lead to mass mortalities and major population crashes [2, 4-8]. Extreme cold events can also have similar fitness consequences. For example, greater flamingos, Phoenicopterus roseus, with lower body condition experienced mass starvation under the combined effect of lower than average winter temperatures and a cold spell that limited access to food [9].

However, in addition to immediate effects of climate extremes, there is growing evidence that repeated exposure to non-lethal climatic conditions can affect body condition and thus has potential to shape selection and hence evolutionary responses. In birds, studies of the effects of non-lethal high temperatures have generally focused on air temperatures in the $30-40{ }^{\circ} \mathrm{C}$ range [8]. Exposure to these temperatures can cause thermal stress and drive reductions in body mass [10-13]. When exposed to air temperatures above about $30{ }^{\circ} \mathrm{C}$, birds actively dissipate heat by evaporative cooling through panting which increases water loss and the potential for mass loss via dehydration $[10,14,30]$. The need to dissipate heat at high temperatures can also lead to tradeoffs with foraging, resulting in reductions in foraging success and loss of body mass [10, 15, 16]. Increasing exposure to temperatures in this range due to climate warming may compromise ability to maintain body mass over longer time-frames with consequences for fitness [10].
In a long-term study of white-plumed honeyeaters, increasing exposure to temperatures $>35{ }^{\circ} \mathrm{C}$ was associated with reductions in body condition; heat-exposed birds in poor condition were less likely to be recaptured in the following spring and were presumed to have died [13].

Cooler weather conditions in autumn and winter can also impose thermoregulatory challenges for endotherms $[17,18]$, and energetic costs of thermoregulation in winter during periods of low food availability can exceed those during the breeding season [19]. Energetic constraints and cold stress can drive reductions in body condition and impose carry-over costs on subsequent survival and reproduction [20-24]. Winter may therefore impose negative longer-term costs on future fitness via carry-over effects on body condition (e.g. [25]. Conversely, relaxation in selection pressures associated with warming winters has been shown to lead to improvement in body condition as well as reduced winter mortality. For example, warming winters led to longer growing seasons with concomitant improvement in the body condition of yellow-bellied marmots, Marmota flaviventris and this was associated with changing patterns of survival and reproduction [26]. Benefits of warming conditions in winter may therefore offset negative effects of warming summers on body condition.

In addition to effects of temperature, rainfall has been shown to have an important influence on body condition in both summer and winter. In cool climates, winter rainfall can reduce the insulation capacity of fur and feathers, thereby increasing heat loss and leading to reductions in body condition [27-29]. Winter rain may also indirectly increase the costs of thermoregulation by negatively affecting the availability of food [27]. In contrast, higher spring and summer rainfall is predicted to have positive effects on body condition in warmer conditions where low water availability might otherwise constrain evaporative cooling and reduce food availability [30]. In addition, high humidity in summer makes evaporative cooling less efficient and could lead to greater challenges from hyperthermia [31].

It is important to understand how climate change may affect body condition, as it is likely to affect fitness, yet there have been few quantitative studies in this area. Studies that have investigated climate-related changes in body condition have tended to focus on migratory populations living at high latitudes where winter conditions are harsh, or on arid zone species where temperature extremes prevail in summer under conditions of low water availability. Here we test for associations between weather and body condition in two sedentary co-existing passerine bird species from temperate south-west Western Australia, red-winged fairy-wrens, Malurus elegans and white-browed scrubwrens, Sericornis frontalis, in populations which have been monitored over 39 years [32]. In a 
recent study of these populations, we showed that winter-related mortality in white-browed scrubwrens was associated with higher frequencies of cold, wet days with thermal minima $<5{ }^{\circ} \mathrm{C}$ [32]. In addition, in both species mortality was associated with carry-over effects of weather conditions in the preceding season, suggesting climate-related changes in body condition may be involved. Here, we test for direct associations and carryover effects between weather variables and body condition, and explore whether body condition may underlie winterrelated mortality. Our study populations have experienced increases in mean temperatures in winter and summer as well as a decrease in the frequency of days with thermal minima $<5{ }^{\circ} \mathrm{C}$ [32]. However, despite a slight increase in the number of days $>35{ }^{\circ} \mathrm{C}$, the summer climate remains relatively mild and no associations with survival were found [32]. We predict that reductions in selection pressures in winter (fewer wet days with minima $<5{ }^{\circ} \mathrm{C}$ ) along with positive effects of increased mean temperatures in both winter and summer, will have positive effects on body condition over time.

\section{Methods}

\section{Study site and study species}

We studied populations of two bird species, white-browed scrubwren and red-winged fairy-wren, that have been subjects of a banding (ringing) program over a 39-year period (1977-2016) at the Smithbrook Nature Reserve southwest of Manjimup in Western Australia $\left(34^{\circ} 20^{\prime} \mathrm{S}, 116^{\circ}\right.$ $\left.10^{\prime} \mathrm{E}\right)$. The 95-ha reserve consists of eucalypt wet forest dominated by Karri Eucalyptus diversicolor, Jarrah E. marginata and Marri Corymbia calophylla with a dense understorey (see [33]).

The focal species are small insectivorous passerine birds that belong to the large and diverse Meliphagoidea [34]. Mean body weight of adults in this study was $9.7 \mathrm{~g}$ (fairy-wren) and $11.2 \mathrm{~g}$ (scrubwren). Both species are sedentary, year-round residents, occupying territories that persist year-to-year $[35,36]$. Both are co-operative breeders, breeding during the austral spring and summer months, producing multiple clutches each season [35, 37]. The species are long-lived: maximum age for red-winged fairy-wrens and white-browed scrubwrens in this study is 15 and 13 years respectively. Both species are sexually dichromatic so adults can be readily distinguished on the basis of plumage.

\section{Data}

\section{(i) Bird data}

The morphometric data are from a long-term banding program [38]. Additional data for red-winged fairy-wrens were available from two detailed studies of the social and mating system of this species based on individually marked, colour-banded birds at the same site. Rowley et al. [33] and
Russell and Rowley [39] monitored individuals from 30 breeding groups between 1980 and 1995. Brouwer et al. [36] monitored individuals from 58 to 70 territories between 2008 and 2016, during which time > 99\% of adult birds were individually colour-banded.

Birds were captured in mist-nets with permission from the Australian Bird and Bat Banding Scheme and weighed with a Pesola balance to an accuracy of $0.5 \mathrm{~g}$ and the primaries were scored for moult. Wing length, an index of structural body size, was measured as the length of the flattened wing chord from the carpal joint to the tip of the longest primary to the nearest $1.0 \mathrm{~mm}$ using a butt-ended ruler [32]. Birds were captured during daylight hours, but mostly between sunrise and 11 am (Australian Western Standard Time). Birds were either of known age or we estimated minimum age of each individual based on recapture data with unknown birds assigned as age one at first capture. We included only adults in our analyses. Our dataset includes a total of 2811 (1460 individuals) captures of red-winged fairywrens caught between 1977 and 2016 and 1587 captures (549 individuals) of white browed scrubwrens caught between 1977 and 2012. We assigned an index of feather wear to account for abrasion to the tips of primary feathers that occurs between successive moults and can affect wing length [32].

\section{(ii) Climate data}

Environmental variables were calculated from standardised daily records from the Pemberton weather station (Station: 009592, $116^{\circ} 00^{\prime} \mathrm{E}, 34^{\circ} 27^{\prime} \mathrm{S}$; Bureau of Meteorology) located ca. $15 \mathrm{~km}$ from the study site. We calculated several weather variables that relate to the capture date of each individual: the number of consecutive wet days $(>0 \mathrm{~mm}$ rainfall) with minimum air temperatures $<5{ }^{\circ} \mathrm{C}$ (NColdWetDays) or consecutive hot, dry days (0 $\mathrm{mm}$ rainfall) with maxima $>30{ }^{\circ} \mathrm{C}$ (NHotDryDays) to which each bird had been exposed immediately prior to capture. We chose these weather conditions because they are known to affect survival in these populations [32] or in other species $[1,23,28]$, and are likely to have consequences for body condition. They comprise the extreme tails of the temperature distribution at the study site, representing the most extreme conditions experienced by these species. Although various studies have identified air temperatures $\geq 35{ }^{\circ} \mathrm{C}$ as thresholds for temperaturerelated mass loss, these are for arid and semi-arid species inhabiting hot environments [10-13]. Species in cooler, mesic climates may have inflections in evaporative water loss at lower air temperatures, in the region of $30{ }^{\circ} \mathrm{C}$ [40]. Furthermore, air temperatures represent a minimum index of thermal stress while operative temperatures will be considerably higher for individuals in non-shaded sites, for example. In small passerines, 
temperatures $<20{ }^{\circ} \mathrm{C}$ can invoke mild hypothermia but air temperatures $\leq 5{ }^{\circ} \mathrm{C}$ are potentially dangerous with increased risk of lethal hypothermia, especially for temperate species that are not cold-adapted [41]. We also calculated total rainfall in $\mathrm{mm}$ in the 30 days prior to capture (Rain30D).

To test for associations between body condition and minimum and maximum temperatures, we extracted the daily minimum temperature on the day before capture (TminDB4) for birds caught in autumn and winter (Apr Sep) and the daily maximum temperature (TmaxDB4) for birds caught in spring and summer (Oct - Mar). To test for carry-over effects of weather in the previous season, we also calculated the numbers of wet days in which autumn and winter temperatures were $<5{ }^{\circ} \mathrm{C}$ in each year (AnnNColdWetDays), and the number of dry days in spring and summer where daily maxima $>30^{\circ} \mathrm{C}$ in each year (AnnNHotDryDays).

Temporal change in climate variables at the study site over the 39 years can be found in [32] (see introduction; Additional file 1: Figure S1). In addition, we tested for temporal changes in seasonal rainfall which we calculated from total rain in autumn and winter (Apr - Sep) in each year and in spring and summer (Oct - Mar) each year.

\section{Models}

\section{(i) Associations between weather and body condition}

Autumn and winter We investigated the effect of low temperatures and rainfall on the body condition of birds caught in autumn and winter (Apr - Sep) by constructing linear mixed models with body mass as the response variable and structural size (wing length) as a co-variate (see below), treating each species separately. Because the majority of body mass measurements were taken in the morning, our body condition measure is a combination of mass gain during the previous day and subsequent overnight mass loss. We fitted minimum temperature (TminDB4) on the day before capture (hereafter called day of exposure) as an explanatory variable because we predicted that decreasing body condition will be associated with decreasing daily minimum temperature, due to increases in the thermoregulatory costs of keeping warm (introduction). We also tested for the effects of exposure to cold, wet days by fitting whether the day of exposure was wet and with minima $<5{ }^{\circ} \mathrm{C}$ (NColdWetDays) (range 0-1 days in our sample); the thermal effects of cold days are pronounced in wet conditions, hence they represent the most extreme conditions. To control for the effect of rainfall on body condition independent of daily minima we also fitted total rainfall recorded in the 30 days prior to capture (Rain30D) because prolonged rainfall can affect food availability and restrict foraging activity leading to reductions in body mass [28]. Last, because carry-over effects of climate are commonly observed between seasons $[32,42]$ we included the number of hot, dry days recording temperatures $>30{ }^{\circ} \mathrm{C}$ (AnnNHotDryDays) in the previous summer as an additional variable. In addition, we accounted for several variables by including them as fixed factors in the model. Body size was included by using residual wing length, whereby we accounted for changes in wing length due to feather wear. Feather wear was calculated from a regression between wing length and abrasion score [32]. We also controlled for sex, day of season (Julian day) and time of day $(24 \mathrm{~h})$ of capture, all of which are known to affect body mass. Although body mass could potentially vary with social status in these cooperative breeders, we do not have data on social status for the complete study duration. However, because age is strongly correlated with social status (since individuals are initially subordinate after which they can become dominant), we included age in our analyses here to account for these possible effects [3]. Year and the identity of individuals were included as random effects to account for the fact that we have multiple data points from the same years and individuals.

Spring and summer We used the same model structure and variables to test for associations between high summer temperatures and body condition for individuals captured Oct - Mar in each year with the following exceptions. Instead of TminDB4 $4_{\text {min }}$ we fitted maximum temperature on the day of exposure (TmaxDB4) as an explanatory variable because we predicted that increasing body condition would be associated with increasing daily maximum temperature in the range $10-30{ }^{\circ} \mathrm{C}$, due to reductions in the thermoregulatory costs of keeping warm. We also tested for the effects of repeated exposure to hot dry days by fitting the number of consecutive dry days with maxima $>30{ }^{\circ} \mathrm{C}$ (NHotDryDays) to which each bird had been exposed immediately prior to exposure (range 0-4 days in our sample). Contrary to winter, higher summer rainfall is predicted to be positively associated with body condition because low water availability can constrain evaporative cooling and reduce food availability. We fitted AnnNColdWetDays to account for carry-over effects of the previous winter on body condition. Other variables included were identical to the winter model (above).

\section{(ii) Temporal changes in body condition}

We tested for changes in seasonal body condition over the 39 years for fairy-wrens and 35 years for scrubwrens, running separate models for birds captured in autumn and winter (Apr - Sep) and those captured spring and summer (Oct - Mar). We fitted year (as a continuous term) and sex as predictors and the interaction term to test whether changes in seasonal condition over time varied between the sexes. In addition, we accounted for 
day in season (Julian day) and age, by including them as fixed effects. Year and the identity of individuals were included as random effects to account for the fact that we have multiple data points from the same years and individuals. Finally, we also tested for annual trends in body condition for each species, combining all captures (spring, summer, autumn, winter) in the same data set, using the same model structure and variables. This allowed us to test whether long-term changes in summer body condition counterbalanced those in winters.

\section{Model fitting}

To account for model selection uncertainty, we adopted a multi-model inference approach based on the Akaike information criteria [43]. We used AIC, corrected for the sample size (AICc) to select the most parsimonious model, with better fitting models resulting in lower AIC values. To avoid multicollinearity among explanatory variables we first estimated pair-wise Pearson's correlation coefficients (Additional file 2: Table S1) and confirmed that correlations were low for all combinations $(|\mathrm{r}|<0.3)$. We generated a candidate set of models with all possible parameter subsets, which were then fitted to the data and ranked by $\triangle \mathrm{AICc}$ values (the difference between each model's AICc and AICc ${ }_{\text {min }}$, that of the "best" model). We report only top models within $\triangle$ AICc of 2 units of the best supported model (see for full model output Additional file 2: Table S1 and Additional file 3: Table S2). Confidence intervals of individual predictor variables were used as indicators of parameter importance [44]. All continuous, explanatory variables were centered around their means and divided by their SD's (z-scores) before including them in the models. All the analyses were conducted in R 3.3.2 [45]; linear mixed models were fitted with maximum likelihood (rather than REML) using the package lme4 [46], and model selection was conducted using the package MuMIn [47].

\section{Results \\ Body condition in autumn and winter \\ Fairy-wrens}

In accordance with the predictions that exposure to cold wet conditions leads to increased thermoregulatory costs, body condition (body mass after accounting for structural body size, measured as wing length) was negatively associated with the exposure to a cold wet day (Fig. 1a). The association with cold wet days was strongly supported, as NColdWetDays was consistently included in the top models (Table 1a). In addition, independent of temperature, body condition was negatively associated with the amount of rain in the previous 30 days (Rain30), which received similar strong support (Fig. 1b; Table 1a). As predicted, higher minimum temperature (TminDB4) on the day of exposure was associated with increased condition (Fig. 1c;
Table 1a). There was no support for a carry-over effect of the preceding summer; including an effect of AnnNHotDays did not improve the model fit (Table 1a, model 2 vs. model 1).

\section{Scrubwrens}

Although the raw data suggested that body condition showed a decrease with exposure to a cold wet day $<5{ }^{\circ} \mathrm{C}$ (Fig. 1d), including NColdWetDays in the model was not supported by the data (Table 1b). As for fairy-wrens, body condition was negatively associated with the amount of rain in the previous 30 days (Fig. 1e; Table 1b) and higher minimum temperatures on the day of exposure (TminDB4) were associated with increased condition (Fig. 1f; Table 1b), although the latter association was less strong in this species (Fig. 1c and f). There was no evidence for carry-over effects of the preceding summer (Table 1b).

\section{Body condition in spring and summer Fairy-wrens}

As predicted, body condition was negatively associated with repeated exposure to hot dry days (Fig. 2a, Table 2a). The raw data suggests that this association only became apparent after two or more hot dry days, although this is based on small sample sizes (Fig. 2a). There was also strong evidence that more rainfall and higher temperatures in summer were positively associated with body condition (Fig. 2b, c), as TmaxDB4 and Rain30 were consistently included in the top models (Table 2a). There was no evidence for carry-over effects of the previous winter, as this model received very limited support and the CI's of the effect of AnnNColdDays overlaps zero (Table 2a, model 1 vs. model 2).

\section{Scrubwrens}

There was no evidence that repeated exposure to hot dry days, rainfall or temperature were associated with body condition (Fig. 2d-f), and including any of these variables resulted in higher AICc values (Table 2b, models 2,5 \& 8 vs. model 1). Furthermore, there was no evidence for carry-over effects of the previous winter (Table 2b, model 9 vs. model 1 ).

\section{Temporal trends in climate and body condition}

Although mean maximum and minimum temperatures increased over the duration of the study period (Additional file 1: Figure S1a, b), annual rainfall remained constant over time. Furthermore, there was no indication that seasonal rainfall patterns changed over time, during either autumn and winter (Apr-Sep: $1.6+$ 2.1 s.e. $\mathrm{mm} \mathrm{yr}^{-1}, t=0.75, P=0.46$ ) or spring and summer (Oct-Mar: $-0.95+1.0$ s.e. $\mathrm{mm} \mathrm{yr}^{-1}, t=-0.923, P=0.36$ ) (Additional file 4: Figure S2a, b). 


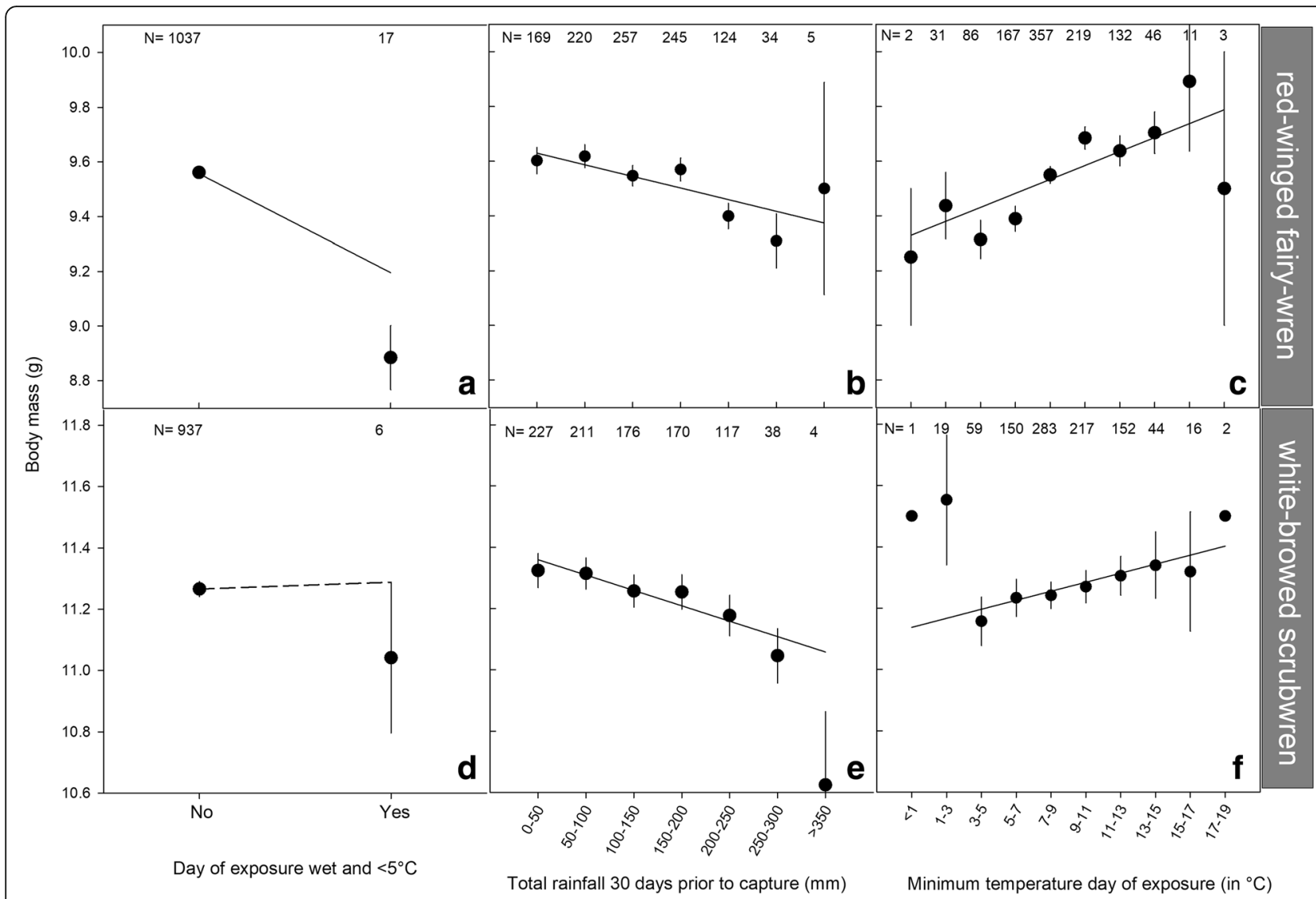

Fig. 1 Associations between winter weather conditions and body mass in winter for red-winged fairy-wrens (a-c) and white-browed scrubwrens $(\mathbf{d}-\mathbf{f})$. Shown are the associations with the day of exposure wet day and $<5^{\circ} \mathrm{C}(\mathbf{a}, \mathbf{d})$, the total rainfall 30 days before capture $(\mathbf{b}, \mathbf{e})$ and the minimum temperature on the day of exposure $(\mathbf{c}, \mathbf{f})$. Lines show the predictions based on the top models from Table $1 \mathrm{a}$ (for $1 \mathrm{a}-\mathrm{c})$ and Table $1 \mathrm{~b}$ (for $1 \mathrm{~d}-\mathrm{f}$ ), with solid lines indicating support $(\Delta \mathrm{AlCc} \geq 2)$ and dashed lines no support $(\Delta \mathrm{AlC} \leq 2)$ Note that the figures are based on raw data and thus are not corrected for any confounding variables (see Table 1)

\section{Fairy-wrens}

Annual body condition of red-winged fairy-wrens, but not scrubwrens increased over time (Table 3c; Fig. 3a) and there was no evidence that this trend varied between the sexes (Table 3c, model 1 vs. model 2). The overall trend for increasing body condition in fairywrens was mainly due to increasing body condition in summer (Table $3 \mathrm{~b}$ ), and the trend of summer condition was stronger for males (Table $3 \mathrm{~b}$, model 1 vs. model 2). There was no support for a trend over time for winter condition (Table 3a, model 1 vs model 2 \&3).

\section{Scrubwrens}

There was some evidence for a negative trend in summer body condition over time for both sexes (Table 3e, model 1 vs. model 2 ), and in winter the temporal trend was also slightly negative for females, whereas condition increased over time for males (Table 3d, model 1). However, both summer and winter effects were weak, as confidence intervals around the parameter estimates cross zero in both cases, and accordingly there was no evidence for overall annual change in body condition for either of the sexes over the 35 years of the study (Table 3f; Fig. 3b).

\section{Discussion}

Our aim was to investigate whether previously recorded associations between climate and survival might be explained by climate-driven effects on body condition in two co-existing species of small insectivorous passerines that have been monitored for 39 years in temperate south-western Australia. In accordance with thermoregulatory expectations, colder daily minima in the range $1-19{ }^{\circ} \mathrm{C}$ were associated with reduced winter body condition in both species. In addition, exposure to a cold, wet day with minima $<5{ }^{\circ} \mathrm{C}$ was associated with a reduction in winter body condition in red-winged fairy-wrens (Fig. 1). In summer, our predictions were only supported for fairy-wrens; warmer daily maxima were associated with increased body condition, whereas repeated exposure to temperatures $>30{ }^{\circ} \mathrm{C}$ was negatively associated with body condition (Fig. 2). In fairy-wrens, body condition 


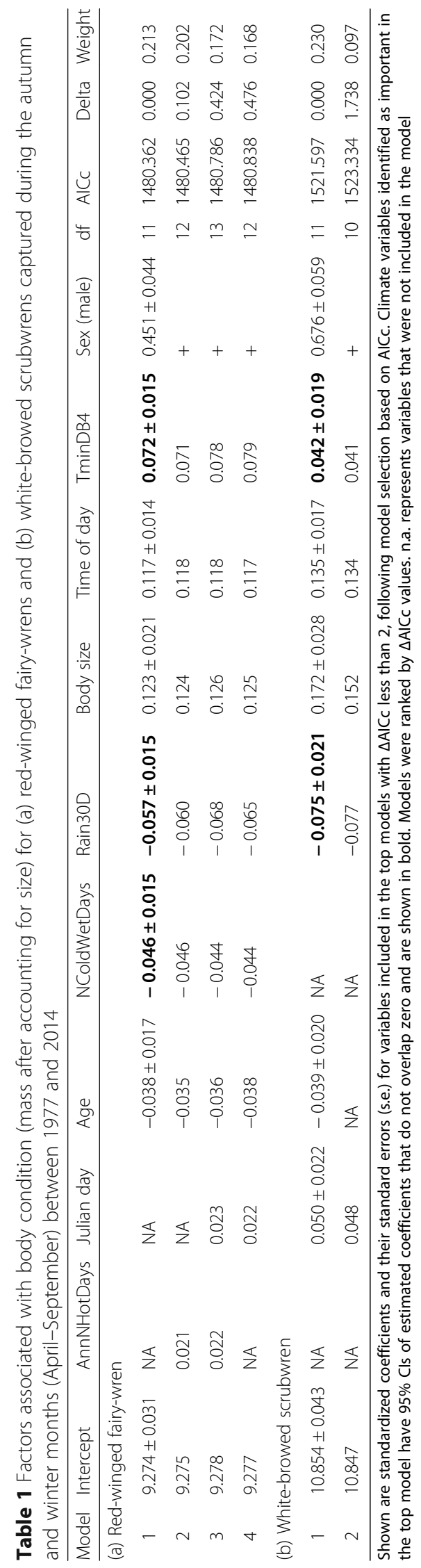




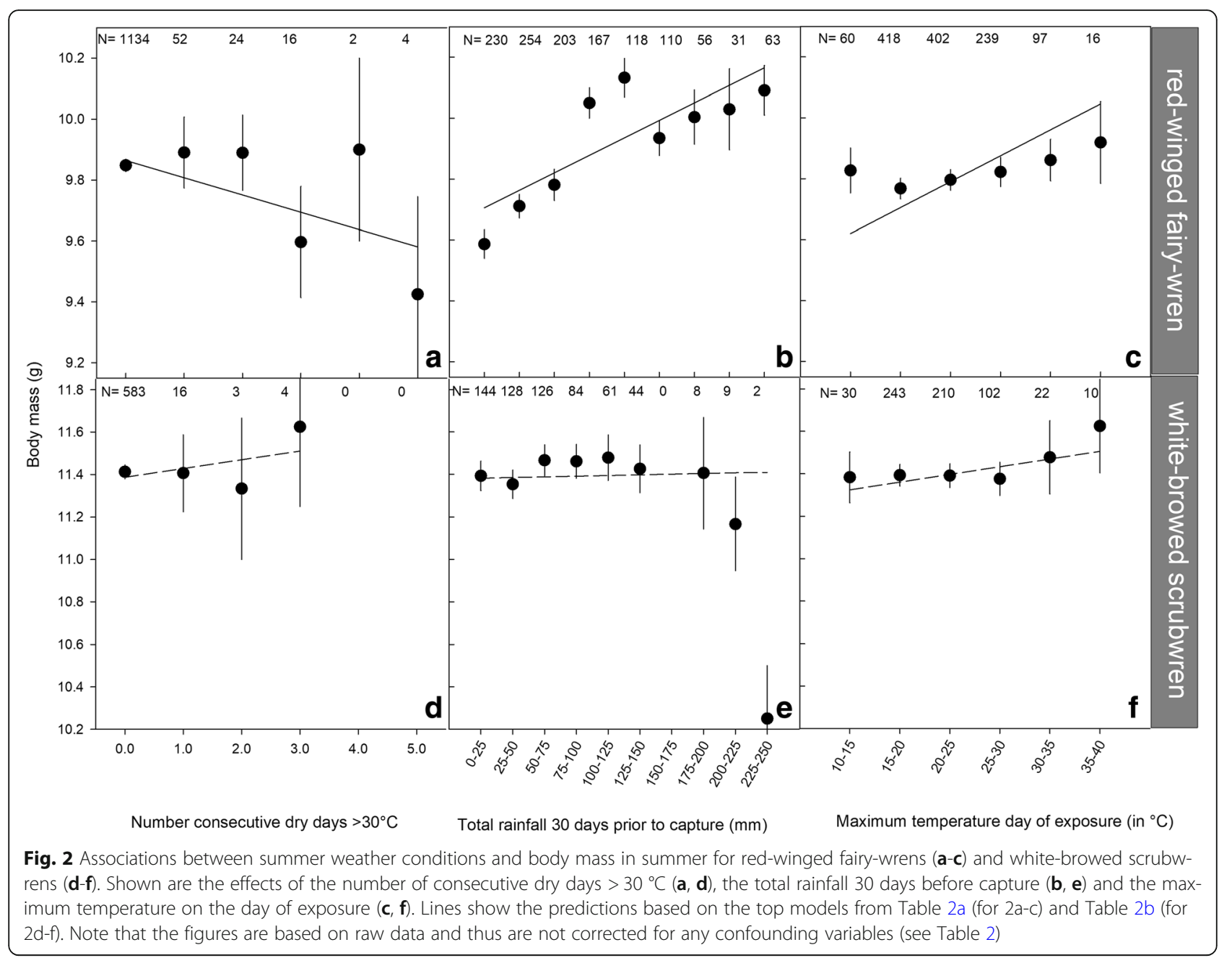

showed a positive trend over time (Fig. 3), consistent with observed within-season associations between body condition and weather and the change in climate over time. The absence in a trend in body condition over time for scrubwrens could be explained by the relaxing selection pressures in winter and the absence of associations between body condition and summer weather. Differences between the two species in their responses to climate may relate to differences in the capacity for behavioural thermoregulation.

\section{Body condition and weather \\ Autumn and winter}

Despite broad interest in the effects of changing climate on fitness and demography, few studies have tested for the effects of warming winters despite strong evidence that increased thermoregulatory costs are associated with winter conditions during periods of low food availability [23, 48, 49]. For birds of both species, decreasing temperature (TminDB4) and higher rainfall (Rain30D) in autumn and winter were associated with reductions in body condition, presumably via increases in the thermoregulatory costs of keeping warm [50]. In the closely related superb fairy-wren Malurus cyaneus, the lower boundary of the thermoneutral zone, which defines the range of ambient temperatures at which resting metabolic rate is at its minimum, is $26{ }^{\circ} \mathrm{C}$ [51]. Below this critical air temperature additional energy may be required to maintain body temperature [52]. Similarly, in the related brown (Lichmera indistincta) and singing (Gavicalis virescens) honeyeaters of similar body size (8-10 and 20-30 g respectively), birds experiencing air temperatures below $12{ }^{\circ} \mathrm{C}$ can become mildly hypothermic, and this was most pronounced in the smaller species [52]. Accordingly, reductions in body condition associated with decreasing temperature in the range $1-19^{\circ} \mathrm{C}$ are consistent with increasing thermoregulatory costs.

Exposure to cold, wet days $<5{ }^{\circ} \mathrm{C}$ was also associated with reduced body condition in autumn and winter, with fairy-wrens having 9\% lower body mass after a cold wet day. Although this predictor was only supported by the data for fairy-wrens, scrubwrens showed 


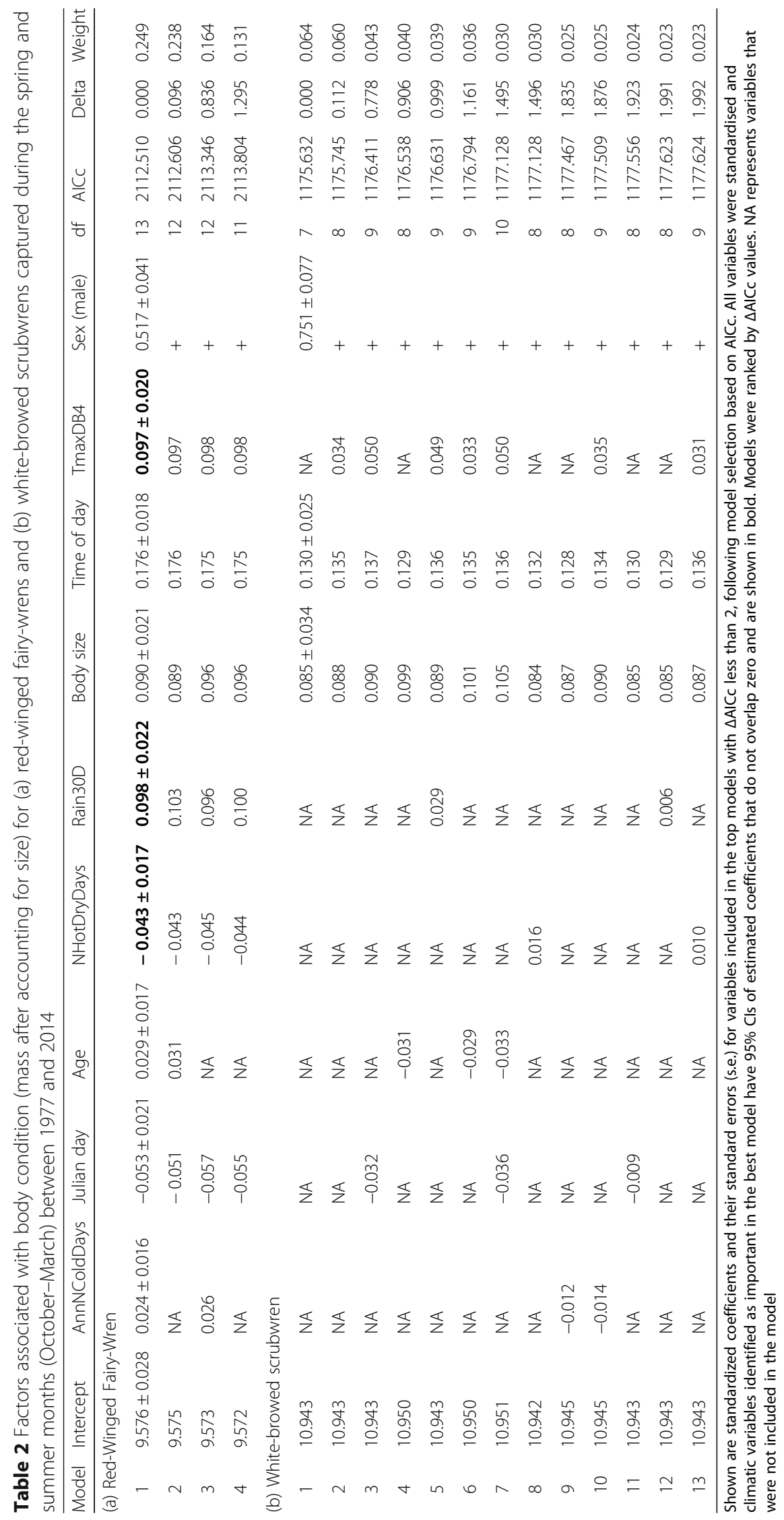


Table 3 Changes in seasonal (autumn and winter, spring and summer) and annual body condition over time for (a, b, c) red-winged fairy-wrens and (d, e, f) white-browed scrubwrens captured between 1977 and 2016

\begin{tabular}{|c|c|c|c|c|c|c|c|c|c|c|c|}
\hline Model & Intercept & Julian day & Age & Year & Sex (male) & Year x Sex & $\mathrm{df}$ & $\log$ Lik & $\mathrm{AlCC}$ & delta & weight \\
\hline \multicolumn{12}{|c|}{ Red-winged fairy-wren } \\
\hline \multicolumn{12}{|c|}{ (a) Winter } \\
\hline 1 & $-0.524 \pm 0.030$ & $-0.041 \pm 0.016$ & $-0.059 \pm 0.017$ & NA & $0.448 \pm 0.040$ & NA & 7 & -790.107 & 1594.320 & 0.000 & 0.399 \\
\hline 2 & -0.527 & -0.038 & -0.065 & 0.053 & + & + & 9 & -788.455 & 1595.083 & 0.763 & 0.273 \\
\hline 3 & -0.526 & -0.038 & -0.064 & 0.015 & + & NA & 8 & -789.771 & 1595.679 & 1.359 & 0.202 \\
\hline \multicolumn{12}{|c|}{ (b) Summer } \\
\hline 1 & $-0.130 \pm 0.027$ & $-0.092 \pm 0.017$ & NA & $0.111 \pm 0.027$ & $0.472 \pm 0.037$ & $0.068 \pm 0.037$ & 8 & -1106.498 & 2229.114 & 0.000 & 0.480 \\
\hline 2 & -0.133 & -0.090 & NA & 0.146 & + & NA & 7 & -1108.158 & 2230.408 & 1.294 & 0.251 \\
\hline \multicolumn{12}{|c|}{ (c) Annual } \\
\hline 1 & $-0.234 \pm 0.021$ & $0.032 \pm 0.011$ & $-0.027 \pm 0.012$ & $0.186 \pm 0.014$ & $0.431 \pm 0.028$ & NA & 8 & -2533.392 & 5082.835 & 0.000 & 0.524 \\
\hline 2 & -0.233 & 0.032 & -0.027 & 0.176 & + & + & 9 & -2533.170 & 5084.405 & 1.570 & 0.239 \\
\hline
\end{tabular}

White-browed scrubwren

(d) Winter

$\begin{array}{lll}1 & -0.275 \pm 0.039 & \text { NA } \\ 2 & -0.280 & \text { NA } \\ 3 & -0.275 & 0.01\end{array}$

(e) Summer

$\begin{array}{lll}1 & -0.218 \pm 0.052 & \text { NA } \\ 2 & -0.218 & -0.035 \\ 3 & -0.231 & \text { NA }\end{array}$

(f) Annual

$\begin{array}{lllll}1 & -0.233 \pm 0.035 & \text { NA } & -0.097 \pm 0.016 & \text { NA } \\ 2 & -0.233 & -0.019 & -0.096 & \text { NA } \\ 3 & -0.232 & \text { NA } & -0.096 & -0.004\end{array}$

$\begin{array}{lll}-0.095 \pm 0.020 & -0.008 \pm 0.044 & 0.448 \pm 0.050 \\ -0.095 & 0.042 & + \\ -0.096 & -0.005 & +\end{array}$

$0.079 \pm 0.044$
NA
+

$\begin{array}{lllll}7 & -611.363 & 1236.910 & 0.000 & 0.283\end{array}$

$\begin{array}{lllll}8 & -610.447 & 1237.131 & 0.221 & 0.253\end{array}$

$\begin{array}{lllll}6 & -612.942 & 1238.022 & 1.112 & 0.162\end{array}$

Shown are standardized coefficients and their standard errors (s.e.) for variables included in the top models with $\triangle$ AlCc less than 2 following model selection based on AICc. All variables were standardized and terms identified as important in the best model have $95 \%$ Cls of estimated coefficients that do not overlap zero and important year terms are shown in bold. Models were ranked by $\triangle \mathrm{AICC}$ values. NA represents variables that were not included in the model

a similar pattern, but sample sizes were very small. At air temperatures below $5{ }^{\circ} \mathrm{C}$ small passerines can become dangerously hypothermic and require substantial amounts of energy to maintain body temperature $[53,54]$. In scrubwrens, previous work has shown that winter mortality in this population was associated with higher frequencies of cold, wet days $<5{ }^{\circ} \mathrm{C}$ [32]. Thus, we suspect that scrubwrens are also affected by cold wet conditions and are possibly even more sensitive than fairy-wrens, with exposure resulting in mortality rather than surviving in poorer condition, as suggested for cliff swallows Petrochelidon pyrrhonota [28]. In our datasets, only a single day of exposure to cold, wet days $<5{ }^{\circ} \mathrm{C}$ was recorded because bird ringers do not work in wet conditions due to the risk of bird mortality. Weather data show that up to 4 consecutive cold, wet days have been recorded over the length of the study which is likely to have a substantial effect on body condition given $9 \%$ loss of body mass recorded in fairywrens after one wet cold day. Nevertheless, differences between species in their response to winter extremes might be explained by differences in behavior: red-winged fairywrens huddle together at night, while scrubwrens apparently roost individually. Huddling at night has been shown to be highly effective in reducing energy expenditure, allowing birds to maintain body mass in cold conditions, which could be particularly important for small-bodied species because they carry limited fat reserves $[53,55,56]$. For example, compared with solitary roosting individuals, Blackcaps, Sylvia atricapilla (mean body mass $18 \mathrm{~g}$ ) that huddled at night spent ca. $30 \%$ less energy on maintaining body temperature at the same air temperatures [57].

\section{Spring and summer}

Warming summer temperatures that are below critical levels are likely to have positive effects on body condition. Here, increasing TmaxDB4 above $13.0{ }^{\circ} \mathrm{C}$ in spring and summer was associated with improved body condition in red-winged fairy-wrens. In scrubwrens, an 


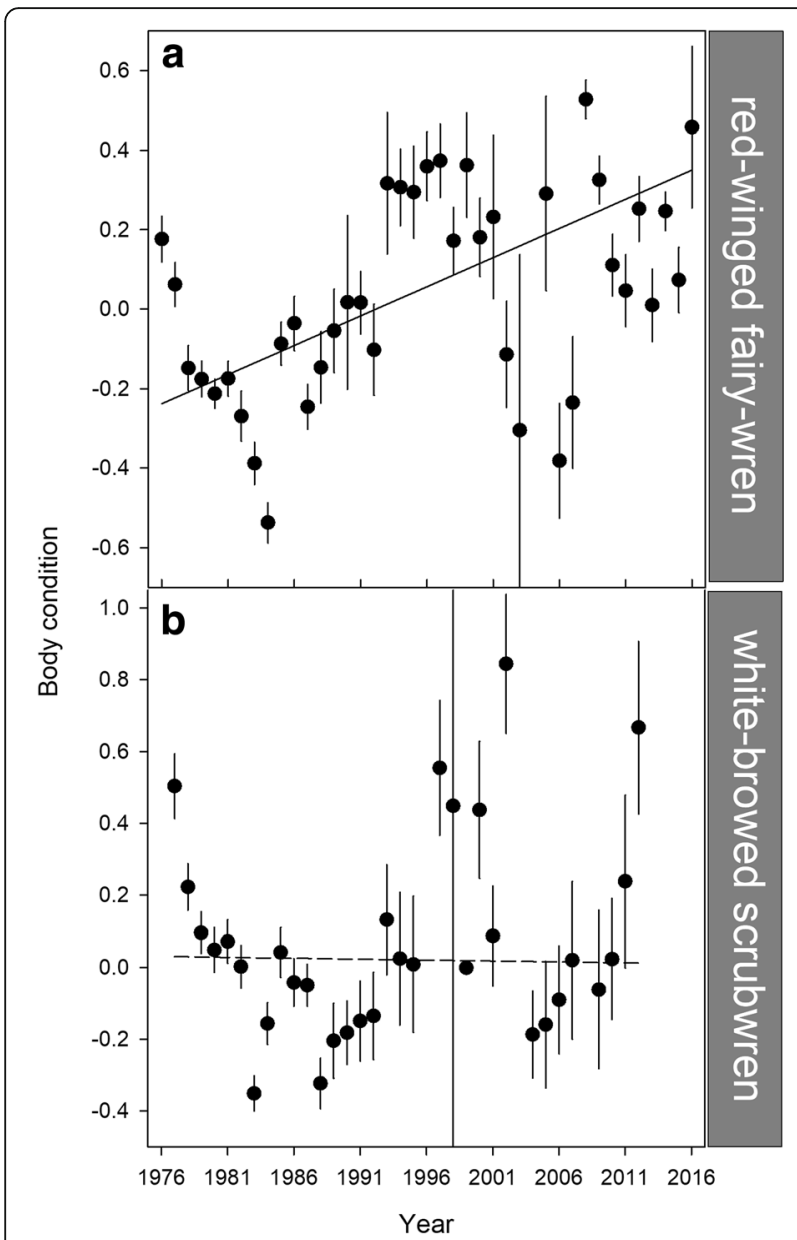

Fig. 3 Annual trend in body condition (residual mass) for (a) red-winged fairy-wrens and (b) white browed scrubwrens. Trendlines show the predictions from the top models from Table 3a (fairy-wrens) and 3d (scrubwrens). Note that the figures are based on raw data and thus are not corrected for any confounding variables (see Table 3)

association between TmaxDB4 and body condition was not supported by the data, although there was a tendency for body mass to increase with maximum daily temperatures (Fig. 2f).

As environmental temperatures approach body temperature, however, birds must allocate energy and water to keeping cool [50], reversing the positive effect of warming temperatures on body condition. Indeed, repeated exposure to temperatures $>30{ }^{\circ} \mathrm{C}$ was associated with reductions in body condition in red-winged fairy-wrens. When environmental temperatures exceed about $30{ }^{\circ} \mathrm{C}$ birds pant to dissipate body heat $[1,30]$. Sustained panting increases the potential for mass loss via dehydration which is predicted to be disproportionately high for small-bodied birds because of their relatively large surface areas [1, 14, 58]. Indeed, several laboratory studies [58-60] suggest that air temperature thresholds for the onset of panting and rates of evaporative water loss scale negatively with body mass, and a recent study of wild-living birds [30] supports these predictions, documenting a negative relationship between temperature-related onset of panting and body mass for species $<200 \mathrm{~g}$.

In the closely related splendid and variegated fairywrens, the HD50 values, an intraspecific behavioural assay that quantifies the air temperature at which $50 \%$ of observed individuals are panting, was $37{ }^{\circ} \mathrm{C}$ at an arid zone site in Western Australia [61], and brown and singing honeyeaters become hyperthermic when air temperatures exceeded $35{ }^{\circ} \mathrm{C}$ [52]. Nevertheless, the climate at our study site is mild compared to these sites, and although maximum summer temperatures have risen over the course of the study there are still few days where temperatures exceeded $35^{\circ} \mathrm{C}$ : only 190 days over 39 years and $<2 \%$ of captures (fairy-wrens: $n=16$, scrubwrens: $n$ $=10$ ) in our dataset experienced these conditions, meaning that we cannot yet test for effects of temperatures > $35{ }^{\circ} \mathrm{C}$. Nevertheless, increases in the frequency of days with air temperatures $>30{ }^{\circ} \mathrm{C}$, when the onset of heat stress and panting may occur [30], may have negative effects on body condition as suggested by our result for red-winged fairy-wrens. In this case, the negative effects of high temperatures become apparent after three or more consecutive hot, dry days $>30{ }^{\circ} \mathrm{C}$ (Fig. 2a), and weather records show that birds may be exposed to up to 8 consecutive days of such conditions. Birds at our temperate study site are not acclimatized to very hot conditions so mass loss associated with repeated exposure to temperatures between 30 and $35{ }^{\circ} \mathrm{C}$ is perhaps not surprising, particularly given recent evidence that temperature thresholds for the onset of panting and heat stress vary among species [30, 57, 62]. Smit and colleagues [30] showed that among 30 species of arid zone birds in South Africa the HD50 values for panting ranged between $31.3-46.0 .{ }^{\circ} \mathrm{C}$ (mean $39.3{ }^{\circ} \mathrm{C}$ ). Future studies should investigate responses to the number of consecutive days of exposure to temperatures above panting thresholds, or the total amount of time above critical thresholds not just the maximum temperature experienced.

Rather than changes in the rates of energy and water use at high temperatures, changes in foraging efficiency or food availability could affect energy and water intake and equally and could account for associations between weather and mass loss observed here. The need to dissipate heat can lead to trade-offs with foraging, resulting in reduced foraging efficiency or effort, leading to reductions in body condition [10, 11]. In addition, nonpanting forms of heat dissipation (e.g. wing drooping), or avoidance of heat exposure (e.g. shade seeking or reducing overall activity levels) can start at air temperatures below those associated with the onset of panting 
[30, 63]. Such activities may reduce energy and water intake, independent of panting-related dehydration or increased rates of energy and water use. Alternatively, direct effects of weather on prey availability (e.g. prey harder to find in hot weather) that affect foraging success, rather than direct effects on physiology or behaviour, could also account for observed patterns.

\section{Temporal trends in body condition over 39 years}

The body condition of red-winged fairy-wrens increased over the course of the study and this was consistent with observed within-season associations between body condition and weather and the change in climate over time. Although winter rainfall has not changed at the site over the 39 years of the study, there has been an increase in minimum winter temperatures and a reduction in thermal extremes (NColdWetDays $<5)$, thereby relaxing selection pressures in winter. Accordingly, the negative associations between body condition and rainfall may be counterbalanced by increasing body condition associated with warming minimum temperatures and the incremental loss of extremely cold days. In combination, this can explain the absence of a change in winter body condition over time for fairy-wrens. Spring and summer temperatures have also risen over time but the negative effects of exposure to summer extremes (NHotDryDays $>30$ ) are as yet minimal, because there are still relatively few extremely hot days observed at the site; body condition decreased only after $\geq 2$ consecutive hot dry days but only $1.7 \%$ of fairy-wrens in our sample were captured after exposure to such conditions. Thus, body condition in summer has increased over time concomitant with rising summer temperatures (TmaxDB4). This effect was stronger for males; perhaps females are unable to benefit in a similar way as males because of the costs associated with nest-building and incubation. Overall, the increase in body condition observed over 39 years could be explained by the increase in body condition in summer, suggesting that recent responses to climate at our study site are driven by warming summers that remain below critical temperatures. This also explains our previous results where we found that fairy-wrens survived winter better after warmer summers presumably because they started winter in better condition, but survival in summer was unrelated to the severity of summer extremes. This highlights the potential importance of carry-over effects of climate on body condition and the links with survival [32]. Nevertheless, as summer temperatures continue to rise resulting in greater exposure to conditions that may induce heat stress, downward trends in body condition appear likely.

In the case of scrubwrens, the combined effects of relaxing selection pressures in winter and the absence of associations between summer weather and body condition can explain why no temporal patterns in body condition where observed.

\section{Differences between the species}

We studied two closely related, ecologically similar species of equivalent body size that inhabit the same site and thus experience the same weather conditions. Despite this, the species differed in their response to weather conditions in that neither the severity of winter conditions (NColdWetDays) or summer weather was associated with scrubwren body condition. The sample size of scrubwrens that experienced a NColdWetDay was smaller than for fairy-wrens, so we cannot rule out the possibility that the power to detect any pattern was simply too low, especially given evidence for winter mortality associated with these conditions (above). However, this cannot explain the absence of a relationship with summer weather.

Sensitivity to climate may be influenced by differences in the capacity for behavioral thermoregulation. Birds use a suite of behaviours and physiological mechanisms to control heat exchange and thus reduce the energy required for thermoregulation. This can include use of micro refugia, postural changes including ptiloerection of feathers, and modification of peripheral blood flow $[29,30,48,52,55,56,63,64]$. Such strategies are used in both winter and summer and can be effective at maintaining body mass in the face of challenging conditions [65]. Differences between the species in diet (e.g. water content of insect prey) and weather-related differences in prey availability could also contribute to differences between species. Although both species are ground-dwelling insectivores, occupying similar ecological niches, detailed behavioural studies are required to identify subtle differences that could affect sensitivity to weather conditions. Finally, a range of factors in addition to the effects of climate may affect body condition, including changes in competition for resources due to density dependent factors, predation pressure or disease, and could also contribute to observed differences between the species.

\section{Conclusions}

The findings of our study have several important implications. We show that associations between body condition and weather variables are complex and dynamic, with seasonal trends in body condition resulting from a balance between multiple, competing weather variables. Moreover, temporal trends in body condition over years could be predicted from the relative strength of seasonal trends and the direction and magnitude of changing climate. Our study demonstrates the value of using a thermoregulatory framework for exploring the consequences of changing climate for body condition. Our previous study identified associations between climate and survival, with sizedependent mortality associated with carry-over effects of climate in the previous season. Here we show that body condition is strongly tied to the same weather variables, suggesting changes in body condition may underlie 
climate-related mortality in these species. Because body condition is predicted to be strongly tied to both reproduction and survival, changes in climate may be having complex and far reaching consequences for demography mediated through shifts in body condition. The pervasive effects on fitness of climate-driven changes in body condition may be at least as significant for population dynamics as the immediate consequences of extreme weather events. Finally, subtle differences in the sensitivities of the species to weather variables led to different trends in condition over time and may be associated with differences in the capacity for behavioural thermoregulation or other factors. Understanding the causes of such sensitivities is vital in improving capacity to predict species responses to climate change.

\section{Additional files}

Additional file 1: Figure S1. Temporal trends in annual climate between 1977 and 2014 at Smithbrook Nature Reserve in southwestern Australia. Shown are (a) annual mean minimum temperature; (b) annual mean maximum temperature [31] (from Gardner et al. [32]). (PDF 331 kb)

Additional file 2: Table S1. Model selection Tables for body condition of red-winged fairy-wrens and white-browed scrubwrens caught in winter and summer, showing the top 100 models. (XLSX 364 kb)

Additional file 3: Table S2. Model selection Tables for temporal trends in seasonal body condition for red-winged fairy-wrens and white-browed scrubwrens caught in autumn and winter (April-September), spring and summer (October-March) and captures in all seasons (spring, summer, autumn, winter), showing all models. (XLSX 62 kb)

Additional file 4: Figure S2. Temporal trends in seasonal rainfall between 1977 and 2014 at Smithbrook Nature Reserve in southwestern Australia. Shown are changes in total rainfall in (a) autumn and winter (April-September); (b) spring and summer (October-March). (PDF 169 kb)

\section{Acknowledgements}

We are grateful to numerous people for assistance in the field, and acknowledge the contribution made by Dick and Molly Brown who set up the study in 1974. We thank Adrian \& Julia Wayne and other staff of the DPAW Science division in Manjimup, John Angus and Karen \& Michael Keely for logistical support and hospitality. Finally, we thank Naomi Langmore, Peter Marsack, Liam Bailey and three anonymous referees for helpful comments on the draft manuscript.

\section{Funding}

LB was supported by a Rubicon Fellowship of the Netherlands Organisation for Scientific Research (NWO825.08.003) and a Fellowship from the Australian Research Council (DE130100174), and JLG was supported by an Australian Research Council Future Fellowship (FT150100139). The compilation of datasets was partly funded by the Wettenhall Environment Trust and undertaken at Monash University while JLG was supported by an Australian Research Council grant (DP120102651).

\section{Availability of data and materials}

Please contact author for data requests.

\section{Authors' contributions}

$J L G$ conceived the study. $L B, E R, P d R$, AdR collected the data and JLG and LB designed the analysis; JLG analysed the data. JLG wrote the manuscript and all authors contributed manuscript feedback. All authors read and approved the final manuscript.

\section{Ethics approval}

The Western Australian Department of Parks and Wildlife (DPAW), the Australian National Animal Experimentation Ethics Committee and the Australian Bird and Bat Banding Scheme gave permission for fieldwork.

\section{Consent for publication}

Not applicable

\section{Competing interests}

The authors declare that they have no competing interests.

\section{Publisher's Note}

Springer Nature remains neutral with regard to jurisdictional claims in published maps and institutional affiliations.

\section{Author details}

${ }^{1}$ Division of Ecology \& Evolution, Research School of Biology, Australian National University, Canberra, ACT 0200, Australia. ${ }^{2} 53$ Swan Street, Guildford, WA 6055, Australia. ${ }^{3} 12$ Glenwood Ave, Glen Forrest, WA 6071, Australia. ${ }^{4}$ Department of Animal Ecology, Netherlands Institute of Ecology NIOO-KNAW, PO Box 50, 6700 AB Wageningen, The Netherlands.

Received: 5 November 2017 Accepted: 8 March 2018

Published online: 27 March 2018

\section{References}

1. Boyles JG, Seebacher F, Smit B, McKechnie AE. Adaptivee thermoregulation in endotherms may alter responses to climate change. Integr Comp Biol. 2011:51:676-90.

2. Huey RB, Kearney MR, Krockenberger A, Holtum JAM, Jess M, Williams SE. Predicting organismal vulnerability to climate warming: roles of behaviour, physiology and adaptation. Philos Trans R Soc Lond Ser B Biol Sci. 2012;367: 1665-79.

3. Monaghan P. Early growth conditions, phenotypic development and environmental change. Philos Trans R Soc Lond Ser B Biol Sci. 2008;363: $1635-45$.

4. Cerrano C, Bavestrello G, Bianchi CN, Cattaneo-Vietti R, Bava S, Morganti C, Morri C, Picco P, Sara G, Schiaparelli S, Siccardi A, Sponga F. A catastrophic mass-mortality episode of gorgonians and other organisms in the Ligurian Sea (north western Mediterranean), summer 1999. Ecol Lett. 2000;3:284-93.

5. Easterling DR, Meehl GA, Parmesan C, Changnon SA, Karl TR, Mearns LO. Climate extremes: observations, modeling, and impacts. Science. 2000;289:2068-74.

6. Welbergen JA, Klose SM, Markus N, Eby P. Climate change and the effects of temperature extremes on Australian flying foxes. Proc R Soc Lond B Biol Sci. 2008;275:419-25.

7. Saunders DA, Mawson P, Dawson R. The impact of two extreme weather events and other causes of death on Carnaby's black cockatoo: a promise of things to come for a threatened species? Pac Conserv Biol. 2011:17:141-8.

8. McKechnie AE, Hockey PAR, Wolf BO. Feeling the heat: Australian landbirds and climate change. Emu. 2012;112:i-vii.

9. Deville A, Labaude S, Jean-Patrice Robin J, Béchet A, Gauthier-Clerc M, Porter W, Fitzpatrick M, Paul Mathewson P, Grémillet D. Impacts of extreme climatic events on the energetics of long-lived vertebrates: the case of the greater flamingo facing cold spells in the Camargue. J Exp Biol. 2014;217: 3700-7.

10. du Plessis KL, Martin RO, Hockey PAR, Cunningham SJ, Ridley AR. The costs of keeping cool in a warming world: implications of high temperatures for foraging, thermoregulation and body condition of an arid-zone bird. Glob Change Biol. 2012;18:3063-70.

11. Cunningham SJ, Martin RO, Hojem CL, Hockey PAR. Temperatures in excess of critical thresholds threaten nestling growth and survival in a rapidlywarming arid savanna: a study of common fiscals. PLoS One. 2014;8:e74613.

12. Kruuk LEB, Osmond HL, Cockburn A. Contrasting effects of climate on juvenile body size in a southern hemisphere passerine bird. Glob Change Biol. 2015;21:2929-41.

13. Gardner JL, Amano T, Sutherland WJ, Clayton M, Peters A. Individual and demographic consequences of reduced body condition following repeated exposure to high temperatures. Ecology. 2016a;97:786-95.

14. McKecknie AE, Wolf BO. Climate change increases the likelihood of catastrophic avian mortality events during extreme heat waves. Biol Lett. 2010;6:253-6. 
15. Edwards EK, Mitchell NJ, Ridley AR. The impact of high temperatures on foraging behaviour and body condition in the western Australian magpie Cracticus tibicen dorsalis. Ostrich. 2015;86:137-44.

16. Cunningham SJ, Martin RO, Hockey PA. Can behaviour buffer the impacts of climate change on an arid-zone bird? Ostrich. 2015;86:119-26.

17. Williams CM, Henry HAL, Sinclair BJ. Cold truths: how winter drives responses of terrestrial organisms to climate change. Biol Rev. 2015;90:214-35.

18. Gallinat AS, Primack RB, Wagner DL. Autumn, the neglected season in climate change research. Trends Ecol Evol. 2015;30:169-76.

19. Sgueo C, Wells ME, Russell DE, Schaeffer PJ. Acclimatization of seasonal energetics in northern cardinals (Cardinalis cardinalis) through plasticity of metabolic rates and ceilings. J Exp Biol. 2012;215:2418-24.

20. Brittingham MC, Temple SA. Impacts of supplemental feeding on survival rates of black-capped chickadees. Ecology. 1988;69:581-9.

21. Källander $H$. The effect of provision of food in winter on a population of the great tit Parus major and the blue tit $P$. caeruleus. Ornis Scand. 1981;12:244-8.

22. Brown DR, Sherry TW. Food supply controls the body condition of a migrant bird wintering in the tropics. Oecologia. 2006;149:22-32.

23. Robinson RA, Baillie SR, Crick HQP. Weather-dependent survival: implications of climate change for passerine population processes. Ibis. 2007;149:357-64.

24. Norris DR, Marra PP, Kyser TK, Sherry TM, Ratcliffe LM. Tropical winter habitat limits reproductive success on the temperate breeding grounds in a migratory bird. Proc R Soc Lond B Biol Sci. 2004;271:59-64.

25. Clausen KK, Madsen J, Tombre IM. Carry-over or compensation? The impact of winter harshness and post-winter body condition on spring-fattening in a migratory goose species. PLoS One. 2015;10:e0132312. https://doi.org/10. 1371/journal. pone.0132312.

26. Ozgul A, Childs DZ, Oli MK, et al. Coupled dynamics of body mass and population growth in response to environmental change. Nature. 2010; 466:482-5.

27. Kennedy RJ. Direct effects of rain on birds: a review. British Birds. 1970; 63:401-4.

28. Brown $C R$, Brown MB. Intense natural selection on body size and wing and tail symmetry in cliff swallows during severe weather. Evolution. 1998;52: $1461-75$.

29. Briscoe NJ, Krockenberger A, Handasyde KA, Kearney MR. Bergmann meets Scholander: geographical variation in body size and insulation in the koala is related to climate. J Biogeogr. 2015;42:791-802.

30. Smit B, Zietsman G, Martin RO, Cunningham SJ, McKechnie AE, Hockey PAR. Behavioural responses to heat in desert birds: implications for predicting vulnerability to climate warming. Clim Change Resp. 2016;3:9.

31. Gerson AR, Krabbe Smith E, Smit B, McKechnie AE, Wolf BO. The impact of humidity on evaporative cooling in small desert birds exposed to high air temperatures. Physiol Biochem Zool. 2014;87:782-95.

32. Gardner JL, Rowley E, de Rebeira P, de Rebeira A, Brouwer L. Effects of extreme weather on two sympatric Australian passerine bird species. Philos Trans R Soc Lond Ser B Biol Sci. 2017;372:20160148.

33. Rowley I, Russell E, Brown R, Brown M. The ecology and breeding biology of the red-winged fairy-wren Malurus elegans. Emu. 1988;88:161.

34. Gardner JL, Trueman JWH, Ebert D, Joseph L, Magrath RD. Phylogeny and evolution of the Meliphagoidea, the largest radiation of Australasian songbirds. Mol Phylogenet Evol. 2010;55:1087-102.

35. Ambrose SJ, Davies SJJF. The social organisation of the white-browed Scrubwren Sericonis frontalis Gould. (Acanthizidae) in arid, semi-arid and Mesic environments in Western Australia. Emu. 1898;89:40-6.

36. Brouwer L, van de Pol M, Atema E, Cockburn A. Strategic promiscuity helps avoid inbreeding at multiple levels in a cooperative breeder where both sexes are philopatric. Mol Ecol. 2011;20:4796-807.

37. Brouwer $L$, van de Pol M, Cockburn A. The role of social environment on parental care: offspring benefit more from the presence of female than male helpers. J Anim Ecol. 2014;83:491-503.

38. Brown RJ, Brown MN, Russell EM. Survival of four species of passerine in karri forests in southwestern Australia. Corella. 1990;14:69-78.

39. Russell E, Rowley I. Demography and social organisation of the red-winged fairy-wren, Malurus elegans. Aust J Zool. 2000;48:161-200.

40. Milne R, Cunningham SJ, ATK L, Smit B. The role of thermal physiology in recent declines of birds in biodiversity hotspot. Conservation Physiology. 2015;3(1):cov048.

41. McKechnie AE, Lovegrove BG. Avian facultative hypothermic responses: a review. Condor. 2002;104:705-24.
42. Harrison XA, Blount JD, Inger R, Norris DR, Bearhop S. Carry-over effects as drivers of fitness differences in animals. J Anim Ecol. 2011;80:4-18.

43. Burnham KP, Anderson DR. Model selection and multimodel inference: a practical information theoretic approach. 2nd ed. Berlin: Springer; 2002.

44. Galipaud M, Gillingham MAF, David M, Dechaume-Moncharmont FX. Ecologists overestimate the importance of predictor variables in model averaging: a plea for cautious interpretations. Methods Ecol Evol. 2014;5: 983-91.

45. R Development Core Team. R: A language and environment for statistical computing. Vienna: R Foundation for Statistical Computing; 2012. Available at: http://www.R-project.org/.

46. Bates D, Maechler M, Bolker B. Lme4: linear mixed-effects models using S4 classes R package. 2012; Available at: http://cran.project.org/web/packages/ Ime4/index.html.

47. Bartoń K. MuMIn: multi-model inference. 2016; R package version 1.

48. Calder WA, King JR. Thermal and caloric relations of birds. In: Farner DS, King JR, editors. Avian biology, vol IV. New York: Academic; 1974. p. p259413.

49. Krams I, Cirule D, Vrublevska J, Nord A, Rantala MJ, Krama T. Noctural loss of body reserves reveals high survival risk for subordinate great tits wintering at extremely low ambient temperatures. Oecologia. 2012;172:339-46.

50. Scholander PF. Evolution of climatic adaptation in homeotherms. Evolution. 1955;9:15-26.

51. Lill A, Box J, Baldwin J. Do metabolism and contour plumage insulation vary in response to seasonal energy bottlenecks in superb fairy- wrens? Aust J Zool. 2006:54:23-30.

52. Collins BG, Briffa P. Nocturnal energy expenditure by honeyeaters experiencing food shortage and low environmental temperatures. Comp Biochem Physiol. 1984;78:77-81.

53. McKechnie AE, Lovegrove BG. Thermoregulation and the energetic significance of clustering behavior in the white-backed mousebird (Colius colius). Physiol Biochem Zool. 2001;74:238-49.

54. Wojciechowski MS, Pinshow B. Heterothermy in small, migrating passerine birds during stopover: use of hypothermia at rest accelerates fuel accumulation. J Exp Biol. 2016;212:3068-75.

55. Chappell MA, Buttemer WA, Andrew F, Russell AF. Energetics of communal roosting in chestnut-crowned babblers: implications for group dynamics and breeding phenology. J Exp Biol. 2016;219:3321-8.

56. Douglas TK, Cooper CE, Withers PC. Avian torpor or alternative thermoregulatory strategies for overwintering. J Exp Biol. 2017;220:1341-9.

57. Wojciechowski MS, Jefimow M, Pinshow B. Heterothermy, and the energetic consequences of huddling in small migrating passerine birds. Integr Comp Biol. 2011;51:409-18.

58. Wolf B. Global warming and avian occupancy of hot deserts; a physiological and behavioral perspective. Rev Chil Hist Nat. 2000;73:395-400.

59. Whitfield MC, Smit B, McKechnie AE, Wolf BO. Avian thermoregulation in the heat: scaling of heat tolerance and evaporative cooling capacity in three southern African arid-zone passerines. J Exp Biol. 2015;218:1705-14.

60. Weathers WW. Physiological consequences of huddling in small migrating passerine birds. Integr comp Biol. 2011;51:409-418. Thermoregulation in heatstressed birds: consequences of body size. Physiol Zool. 1981;54(3):345-61.

61. Russell G. Functional traits contribute to the survival of Australian desert birds during extreme heat functional traits contribute to the survival of Australian desert birds during extreme heat: Hons Thesis. Perth: The University of Western Australia; 2012.

62. McKechnie AE, Gerson AR, McWhorter TJ, Krabbe Smith E, Talbot WA, Wolf BO. Avian thermoregulation in the heat: evaporative cooling in five Australian passerines reveals within-order biogeographic variation in heat tolerance. J Exp Biol. 2017:220:2436-44.

63. Martin RO, Cunningham SJ, Hockey PAR. Elevated temperatures drive finescale pattern of habitat use in a savanna bird community. Ostrich. 2015;86: 127-35.

64. Austin GT, Miller JS. Temperature-related behavior of some migrant birds in the desert. Western north. Am Nat. 1982:42:232-40.

65. Moore AD. Winter night habits of birds. Wilson Bull. 1945;57:253-60. 